\title{
A description of patients with recurrence of Pulmonary Tuberculosis in a Tuberculosis Hospital, Ermelo
}

\author{
Authors: \\ Ubon S. Akpabio ${ }^{1}$ \\ Pierre JT. de Villiers ${ }^{2}$ \\ Affiliations: \\ ${ }^{1}$ Ermelo Provincial Hospital, \\ Ermelo, Mpumalanga \\ Province, South Africa \\ ${ }^{2}$ Department of \\ Interdisciplinary Health \\ Sciences, Stellenbosch \\ University, South Africa \\ Correspondence to: \\ Ubon Akpabio \\ Email: \\ Akpabio@telkomsa.net \\ Postal address: \\ Postnet Suite 911, Private \\ Bag X9013, Ermelo, 2350, \\ South Africa \\ Dates: \\ Received: 04 Dec. 2010 \\ Accepted: 12 Apr. 2011 \\ Published: 01 Nov. 2011 \\ How to cite this article: \\ Akpabio US, De Villiers JTP. A \\ description of patients with \\ recurrence of Pulmonary \\ Tuberculosis in a Tuberculosis \\ Hospital, Ermelo. Afr J Prm \\ Health Care Fam Med. \\ 2011;3(1), Art. \#261, 8 pages. \\ http://dx.doi.org/10.4102/ \\ phcfm.v3i1.261
}

C 2011. The Authors.

Licensee: AOSIS

OpenJournals. This work

is licensed under the

Creative Commons

Attribution License.
Background: Retreatment TB (tuberculosis) is a serious category of pulmonary TB with a treatment outcome that could include MDR-TB (multidrug resistant TB). In the Msukaligwa municipality of Mpumalanga Province, South Africa, the burden of TB is high with poor treatment outcome indicators, thus creating some preconditions for retreatment TB. Knowledge of the characteristics of the patients and related health system factors would help in designing interventions to improve the care for patients, the adherence to medication and the prevention of retreatment $\mathrm{TB}$.

Aim of the study: The aim was to describe the occurrence, characteristics and management outcome of retreatment pulmonary tuberculosis in patients in a TB hospital in Ermelo.

Objectives: The specific objectives were to describe the socio-demographic, behavioural and clinical factors related to recurrence of TB in patients; to determine the contribution of defaulting treatment to recurrence of TB in the study population; to identify the prevalence of resistance to $\mathrm{TB}$ medication amongst patients with retreatment $\mathrm{TB}$; and to identify treatment outcomes in patients who have been followed up for the duration of retreatment TB.

This study was set in the 58-bed TB hospital in Ermelo.

The study design was cross-sectional and descriptive, and the study population comprised of patients admitted with TB at the Ermelo TB hospital between 01 January 2005 and 31 December 2007. Data were collected from the patients' medical records and the TB registers by using a predesigned form. Data were analysed with Microsoft Excel Spreadsheet at the Centre for Statistical Consultation at the University of Stellenbosch.

Results: All of the 388 patient records with retreatment TB, which formed $19.6 \%$ of TB patients admitted between 2005 and 2007, were reviewed. This comprised $66 \%$ male patients with a mean age of 41.4 , and $34 \%$ female patients with a mean age of 35.3 . They were mostly unemployed, and $93 \%$ had a primary education; $43 \%$ were unmarried and $34 \%$ were married. Retreatment TB was diagnosed with sputum smear microscopy in $71 \%$, with a bacilli load of $3+$ in $45 \%$ of the patients. Almost three-quarters $(74 \%)$ of the patients have been afflicted by TB, 1-3 years before the episode under study. Retreatment TB categories were: 'after treatment completed', 69\%; 'default', 19\%; 'after cure, 8\%, and 'treatment failure', $4 \%$. The majority, that is, $98 \%(169 / 172)$ of patients tested, had a HIV-positive status; the median CD4 cell count was 106 cells $/ \mu \mathrm{L}$ at the time of retreatment, and very few (5\%) were on ART (antiretroviral drug treatment). Drug resistance to primary TB drugs was as follows: Rifampicin (16\%), Isoniazid (29\%), Ethambutol $(19 \%)$, and Streptomycin $(23 \%)$. The treatment outcomes for those for whom data were available were: 'successful' (49.1\%), 'death' (23.8\%); and 'treatment default' (22.9\%). MDR-TB caused complications in $3.3 \%$ of the patients.

Conclusion: The majority of the retreatment TB patients were male patients with an average age of 41, and unemployed. More than two-thirds of the patients had completed TB treatment previously, and defaulting treatment accounted for less than one-quarter of retreatment categories. The process of care was better in terms of the diagnosis of TB with sputum smear. Improvement in the documentation of key factors such as smoking, alcohol, drug use amongst patients and co-morbidity, as well as counselling and testing for HIV and provision of ARTs, is required. Treatment outcomes with regard to successful outcomes should be monitored and improved.

\section{Introduction}

Tuberculosis (TB) is a major public health problem worldwide, and during 1993 the WHO (World Health Organisation $)^{1}$ has proclaimed it a public health emergency. South Africa is one of the highburden countries for TB with an excessive annual estimated incidence. ${ }^{2}$ The WHO global report on 
TB in the 2005-estimate, places the incidence of TB in South Africa at 245 cases (200-302) per 100000 population per year, and prevalence at $344-718$ cases per 100000 population. It is also estimated that mortality caused by TB, varies between 47 and 107 deaths per 100000 patients (71/100 000), and that the proportion of new adult TB patients of age 15-49 who are HIV-positive, is 58\% (49\% - 65\%); new TB patients who are multidrug resistant are estimated at $1.8 \%(1.4 \%-2.3 \%)$ and previously treated TB patients who were multidrug resistant in 2002 , are estimated at $6.7 \%(5.5 \%-8.1 \%){ }^{2}$

In the Mpumalanga province of South Africa, the burden of tuberculosis reflects the national trend. The incidence of TB in the Msukaligwa municipal area is estimated as the second highest in the district at about 450 per $100000 . .^{3}$ The available health indicators for 2006 for tuberculosis in the Msukaligwa municipal area, indicate a serious problem with the following: a Cure Rate of $40 \%$; the Smear Conversion at the end of the intensive phase, 35\%; and the Defaulter Rate, $27.5 \%{ }^{3}$

Improper treatment and default on treatment could result in TB bacilli developing resistance to treatment with serious consequences for the patient and the general population. Patients who present with retreatment pulmonary TB represent a group that could eventually lead to the development of drug resistance. Understanding the characteristics of these patients will help in designing interventions that will prevent non-adherence to treatment and enhance a high cure rate for patients with TB in the health care system, as well as minimise the burden of retreatment pulmonary TB on health care facilities and the community.

\section{Setting}

The setting of this study is a 58-bed TB hospital in Ermelo, Msukaligwa municipality, of the Gert Sibande district of Mpumalanga. It is one of the two specialised TB hospitals in the district with facilities for the admission of adult TB patients. Patients for admission are referred from the one regional, the five district hospitals, the primary health care clinics, and private doctors, in the Gert Sibande district.

All retreatment TB patients who are ill and live far away from the hospital are usually admitted for an initial period of 6-8 weeks. During this admission, sputa are collected at intervals specified in the National TB Treatment Guidelines and the retreatment regimen commences. Decisions on the continuation of treatment, sputum culture, drug sensitivity and treatment failure are made, depending on the sputum smear results at these periods. On discharge, patients can be reviewed monthly as outpatients in the hospital, or followed up at the nearest primary health care clinics in their area. All patients who choose to be followed up at the clinics are provided with referral letters for the clinic sister. At the clinic they are referred for supervision of treatment under the DOTS (Directly Observed Treatment, Short-course) programme and will visit the clinic on a monthly basis to collect their medication, until the treatment is completed.
Retreatment tuberculosis occurs after a person may, or may not, have completed the scheduled treatment course for TB. It can occur because of endogenous reactivation or exogenous re-infection. ${ }^{4,5}$ In the South African National TB Control Program, ${ }^{6}$ various categories of retreatment TB have been identified. The rates of recurrence of TB has been found to vary in various studies from $0 \%$ to $14 \%$ in one study, whilst a study ${ }^{8}$ amongst South African miners gave a rate of 10.3 episodes per 100 person-years at risk during a followup period of 25.1 months. In yet another study, ${ }^{9}$ a rate of $18 \%$ was indicated. Recurrence was found to be associated with poor treatment adherence and occurred after successful treatment, as well as after default on treatment.

An episode of retreatment TB could be a consequence of a TB relapse or a reinfection with a new $\mathrm{TB}$ strain. This differentiation can be performed by using DNA fingerprinting techniques with Mycobacterium TB. $8,9,10,11,12,13,14$ Whether retreatment TB in a patient is due to reinfection or reactivation is not clinically distinguishable. The mechanisms that have been postulated as leading to the development retreatment $\mathrm{TB}$ in patients are either endogenous and true treatment failure or exogenous reinfection. In an area of low TB incidence and low HIV prevalence, studies have revealed that reinfection with a new $M$. tuberculosis strain is considered a rare cause of recurrent TB. ${ }^{14,15}$ This contradicted the findings in a population-based retrospective case control study ${ }^{16}$ in Houston, USA, where reinfection with a new strain of M. Tuberculosis was the cause of recurrent TB.

In a setting of high TB and HIV prevalence respectively, as in South Africa, ${ }^{2}$ the relative contribution of reinfection or relapse to recurrent TB is different. A study ${ }^{10}$ amongst South African mine workers indicated that most recurrent TB was due to relapse within 6 months, with reinfection common in patients with HIV infection, compared to an earlier study in South Africa ${ }^{12}$ using DNA fingerprinting which provided evidence that reinfection was the cause of recurrence of tuberculosis.

Non-adherence to TB treatment resulting in retreatment TB has been extensively studied, particularly in countries with a high burden of TB disease. The factors responsible can be categorised under personal (age, gender, marital status), ${ }^{17,18,19,20,21,22,23,24}$ socio-economic or behavioural (employment, income, alcohol use),,$^{26,27,28,29,30,31,32}$ comorbid, ${ }^{33,34,35,36,37,38}$ health system, ${ }^{39,40,41}$ as well as community and family related groups. The issues of support from family or friends during treatment could reflect community beliefs, attitudes and stigma attached to TB and has been found to play a crucial role in defaulting. ${ }^{32}$

\section{Significance of the study}

The aim of the study was to describe the occurrence, associated factors and management outcomes of retreatment pulmonary tuberculosis in patients in the Ermelo TB hospital. 


\section{Ethical considerations}

Ethical approval was granted by the Committee for Human Research at the University of Stellenbosch and the Research Ethics Committee of the Department of Health, Mpumalanga.

\section{Methods}

\section{Design and materials}

The study design was descriptive. The study population comprised of all patients admitted with TB at the TB hospital in Ermelo over a 3-year study period. The sample for the actual study population comprised all patients aged 15 and older who have been diagnosed with retreatment TB and who have commenced with TB treatment between 01 January 2005 and 31 December 2007. These are patients who have been entered in the hospital-based TB register with medical records available in the hospital. Patients excluded were those with extra pulmonary $\mathrm{TB}$, and patients with retreatment TB who started with treatment in 2004 and completed their treatment in 2005.

The required information was extracted from the TB register and patients' medical records and entered into the data collection form that was used for each identified patient. The data collection form had three-digit serial numbers with no patient identifiers on it, but could be cross-referenced with the medical record if necessary. Information for analysis was derived from the data collection form and entered into the Microsoft Excel spreadsheet designed for the analysis.

The reliability of the data collected was assured by clearly defining the terms and concepts relevant to the study. For this, the case definitions, as contained in the South African National TB control programme guidelines, were used. This applied to definitions such as 'retreatment $\mathrm{TB}^{\prime}$; 'retreatment categories'; 'treatment outcomes' and 'drug resistance'. To ensure the validity of the data collected, reference was made to each of the patients' records to ensure that the information reflected in the TB register corresponded to the patient's medical record.

\section{Procedure}

The data collection involved visits to the Ermelo TB hospital during the period of the data collection. The total number of patients treated over the study period was ascertained from the TB register and patients with retreatment TB were identified. Medical records of the patients identified in the TB register, were requested in order to extract detailed information about each patient, based on the data collection tool developed for this purpose.

\section{Analysing}

The data were analysed with Microsoft Excel Spreadsheet at the Centre for Statistical Consultation, University of Stellenbosch. The data collection form served as a guide to design the spreadsheet on which data on each of the variables contained in the questionnaire were entered, and subsequently analysed. This was a descriptive study and therefore the data analysis expresses the prevalence of various factors associated with retreatment TB using summary statistics. The data are presented mainly in the form of a histogram chart and tables, reflecting the variables of interest to the study.

\section{Definitions}

The diagnosis of tuberculosis was considered to be based on any of the following: microscopy-sputum smear and standard reporting of the bacilli load; clinical evaluation of the patient (history, symptoms and signs of illness, and a physical examination); and chest radiography interpretation. In addition, any patient with TB who was on treatment with Regimen 2 was considered to have retreatment $\mathrm{TB}$ and in the absence of any documentation this was taken as pulmonary TB. In order to facilitate the collection of the required data, all the definitions applied to the study were those defined in the South African TB Control Programme Practical Guidelines $2000,{ }^{6}$ as well as the definitions in national TB register. The following are definitions that are relevant to this study.

\section{Retreatment TB Categories}

Retreatment TB after treatment completed: the patient had completed the course of treatment but no proof of cure is provided by the sputum smear test, but the patient now smear positive.

Retreatment TB after cure: the patient was treated and became smear-negative on completion of the treatment and now smear positive.

Retreatment after default or interruption: the patient interrupted the initial treatment for 2 or more months. The patient may be smear-positive or smear-negative, but still has active TB according to clinical or radiological assessment.

Retreatment after failure: The patient is on treatment but remained smear-positive 5 months or later after commencing TB treatment.

\section{Retreatment TB Outcomes}

Cured: the patient is smear-negative at, or 1 month prior, to completion of the treatment, and on at least one previous occasion.

Completed: the patient has completed the treatment course but there is no proof of cure from the sputum test, that is, no smear-negative result is available.

Failure: the patient on treatment remained or became smearpositive 7 months or later after commencing treatment.

Death: the patient died during the course of treatment (regardless of the cause of death). 
Default: the patient interrupted the treatment for 2 or more months.

\section{Results}

A total of 388 patients with retreatment TB were seen at the TB Hospital between 2005 and December 2007. These constituted $19.6 \%$ of the 1980 patients, in total, treated for TB during the period. There were $66.0 \%$ male and $34.0 \%$ female patients, with a resulting male : female ratio of $1.9: 1$.The mean age for the male patients was 41.4 years and 35.3 years for the female patients. For both sexes, the most affected age group was 35-44 for men, and 25-34 for women (Table 1). Ninety-three percent $(93.0 \%)$ had primary education, $2.0 \%$ had high school education and $6.0 \%$ had no formal education; $74.7 \%$ were unemployed. Information on social habits revealed the following: smoking, alcohol and drug use was not known for $98 \%$ of the patients. With regard to marital status, $43.0 \%$ were unmarried; in $23.0 \%$ the marital status was not known; $34.0 \%$ were reported as married. The following data were available on the number of people in the same household, excluding the patient at the time of the episode of retreatment TB treatment: the majority $(72.0 \%)$ of the patients lived in households with least 2 persons.

The majority $(97.0 \%)$ of the patients had TB once in the past and $74.0 \%$ of these patients had TB in the past $1-3$ years before the episode under study. With regard to the diagnostic process for TB, most of the TB (71.0\%) was diagnosed by Sputum microscopy (Table 2). The retreatment TB categories at the time of diagnosis (Table 3), and information on the drug sensitivity testing pattern for the primary TB drugs (Table 4) have been reflected. Records were available for analysis for about $25.9 \%$ (100/386) of the patients. With regard to drug sensitivity, more patients $(29.0 \%)$ were resistant to Isoniazid compared to $16.0 \%$ for Rifampicin. In terms of treatment outcome (Table 5), successful outcomes were $49.1 \%$ for 'cured and completed treatment'; 'failure', 4.2\%; 'default', $22.9 \%$ and 'death', 23.8\%, amongst those who were followed up at the TB hospital. MDR-TB resulted from 3.3\% (7/214) of the patients followed up in the hospital. The 'Treatment Outcomes' for the retreatment TB. MDR-TB is included in the Failures. It is a serious complication of retreatment TB and not a treatment outcome.

\section{Discussion}

Although the proportion of retreatment TB in this study may not estimate directly the extent of retreatment TB in the population, it, however, gives some indication of the burden of this problem on the health system within the context of the already high prevalence of TB and HIV diseases in the community. It reflects a fair measure of the load of TB patients that the health care workers and the institution have to cope with. Various studies ${ }^{7,8}$ have given estimates of retreatment TB in the patient population. In a systematic review of long term efficacy of DOT regimes ${ }^{7}$, the rates of retreatment TB was found to vary from $0 \%$ to $14 \%$ after successful treatment whilst a study ${ }^{8}$ amongst South African miners found a rate of 10.3 episodes per 100 person-years at risk during a follow-up of patients for the median period of 25.1 months with most recurrence occurring within the first 6 months of followup of patients. This study found that $74 \%$ of patients had contracted TB, 1-3 years before the current episode, which compares with the Malawian ${ }^{47}$ study that found that $60 \%$ of patients had another episode of TB within the first 2 years of completing treatment.

This study has also revealed some personal factors associated with retreatment TB amongst the patients studied. Most of the patients with retreatment TB were men with a mean age of 41.4 years compared to women who were relatively younger at an average age of 35.3 years. The mean age of female patients was at least 6.1years less than that of male patients. Whilst there have not been consistent findings on the effect of gender and default from TB treatment, most studies had shown that male patients are more likely to default with TB treatment than female patients. This may partly explain the relative large proportion of male participants with retreatment TB in this study. The finding of this study with regard to male patients is similar to others that have been reported from studies in Turkey, Nigeria and India. In the Turkish study, ${ }^{25}$ the risk factors for non-successful treatment were determined to be retreatment patients older than 46 , whilst in the Nigerian study, ${ }^{18}$ the $44.2 \%$ who defaulted on their treatment were older than 65 , and in India, ${ }^{20}$ not completing the process of diagnosis of TB was higher in the age group older than 50 years.

The prevalence of behavioural and social factors like unemployment, smoking, alcohol and drug use in patients

TABLE 1: Age and sex distribution of retreatment tuberculosis patients $(N=388)$.

\begin{tabular}{|c|c|c|c|c|c|c|}
\hline \multirow{2}{*}{$\begin{array}{l}\text { Age Group } \\
\text { Years }\end{array}$} & \multicolumn{2}{|c|}{ Male patients } & \multicolumn{2}{|c|}{ Female patients } & \multicolumn{2}{|c|}{ Total patients } \\
\hline & $n$ & $\%$ & $n$ & $\%$ & $n$ & $\%$ \\
\hline $15-24$ & 6 & 1.5 & 15 & 3.9 & 21 & 5.4 \\
\hline $25-34$ & 64 & 16.5 & 56 & 14.4 & 120 & 30.9 \\
\hline $35-44$ & 94 & 24.2 & 37 & 9.5 & 131 & 33.8 \\
\hline $45-54$ & 64 & 16.5 & 20 & 5.2 & 84 & 21.6 \\
\hline $55-64$ & 23 & & 5 & 1.3 & 28 & 7.2 \\
\hline$\geq 65$ & 4 & 1.0 & 0 & 0.0 & 4 & 1.0 \\
\hline Total & 255 & 65.7 & 133 & 34.3 & 388 & 100 \\
\hline
\end{tabular}

Source: Authors' Original data

$N$, The total number of patients; $n$, Given as a means of number. 
TABLE 2: Distribution of retreatment tuberculosis patients according to how tuberculosis was first diagnosed $(N=388)$.

\begin{tabular}{lcc}
\hline Main Diagnostic tool & $\boldsymbol{n}$ & $\mathbf{\%}$ \\
\hline Sputum AFB & 276 & 71.1 \\
Chest X-Ray & 93 & 24.0 \\
Others (Pleural fluid ADA) & 19 & 4.9 \\
\hline
\end{tabular}

Source: Authors' Original data

$N$, The total number of patients; $n$, Given as a means of number; AFB, Acid-fast bacilli; ADA Adenosine deaminase.

TABLE 3: Distribution of Retreatment tuberculosis patients by retreatment tuberculosis category based on previous tuberculosis episode $(N=388)$.

\section{Retreatment TB Category}

After treatment completed

After cure

After default

After failure

Source: Authors' Original data

$N$ The total number of patients; $n$, Given as a means of number; TB, tuberculosis.

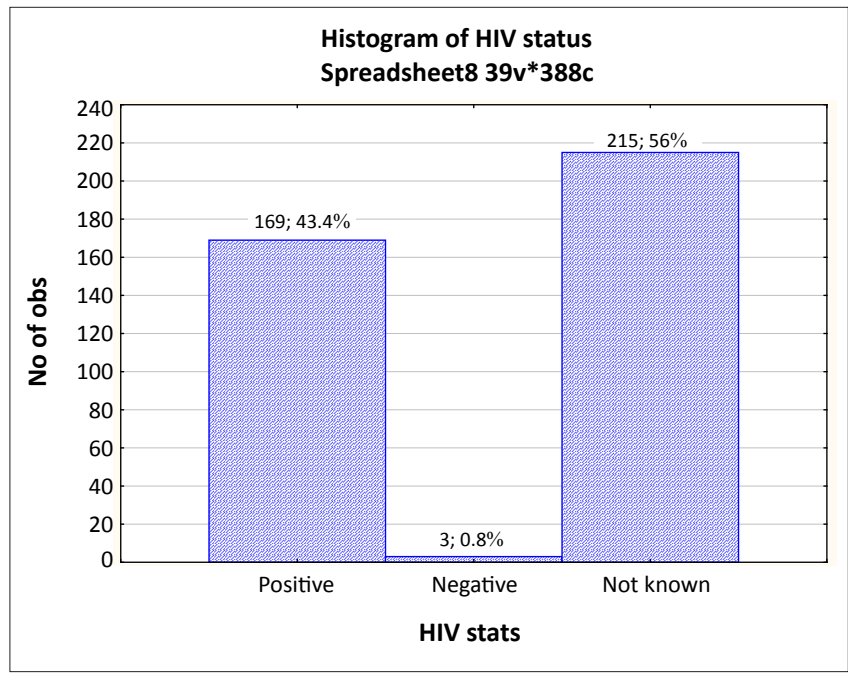

Source: Authors' Original data

$N$, The total number of patients.

FIGURE 1: Distribution of retreatment TB patients by HIV status $(N=388)$.

with retreatment TB has also emerged from the study. Seventy five per cent of the study population indicated that they were unemployed at the time of treatment. This is the only social factor that was found in the study and compares well with what has been reported in studies in other parts of the world like Nepal, Russia and Brazil ${ }^{26,27,28}$ as one of the reasons for defaulting on TB treatment, which resulted in retreatment TB. There were little data on smoking, alcohol and drug use as it was not documented in the records. This is an important omission in the process of care of these patients which should be remedied and it should be realised that there is some linkage between these social habits and retreatment TB.

There was some limited information on the HIV status of the patients with retreatment TB. Information on the HIV status was available for only $44.2 \%$ of the patients in this study (Figure 1). This low proportion could be related to the lack of capacity to offer voluntary counselling and testing to all patients and recording the results in the patients' files. Amongst those who were tested, data indicate that $98.3 \%$ were HIV-positive. A previous study ${ }^{34}$ amongst South African miners has indicated that HIV infection was associated with significantly increased rates of recurrent TB with an incidence of 8.2 per 100 person-years in HIV-positive compared to 2.2 per 100 person-years in HIV-negative men. The need to test patients is recognised in the hospital; however, patients can decline after voluntary counselling.

Another HIV-related factor to the recurrence of $\mathrm{TB}$ is the level of immune-compromise as reflected by the CD4 counts. Information on this was available for a very small number of patients. Other studies ${ }^{48,49}$ have showed that the risk of developing recurrent $\mathrm{TB}$ is increased as the immunity worsens with declining CD4 counts. In this study, the median CD4 count for those that were available was low at 106 cells/ $\mu \mathrm{L}$. The use of ART was found to be very limited in the study patient population. This was not unexpected as the roll out of ART in public sector was only initiated within the period of the study, hence most of those HIV-positive patients at that time did not have access to such services.

The study also revealed information on drug sensitivity patterns amongst patients. There was a large proportion of non-documentation relating to drug resistance and sensitivity to TB drugs used, as data was only available for $25.9 \%(100 / 386)$ of the patients studied. The low proportion of sensitivity testing reflects a serious lack of attention to this aspect of the care process for TB patients with regard to documentation in the patient files. The drug resistance to primary $\mathrm{TB}$ drugs varied from $16 \%$ for Rifampicin to $29 \%$ for Isoniazid. The level of resistance to any of the TB drugs is high when compared to other reported studies from Saudi Arabia ${ }^{42}$ and South Africa. ${ }^{43,44,45,46}$ The findings of this study underlines the fact that resistance to any TB drug is significantly more probable in patients with retreatment pulmonary TB. The significance of this resistance lies in

TABLE 4: Distribution of retreatment tuberculosis patients by drug sensitivity testing profile.

\begin{tabular}{|c|c|c|c|c|c|c|c|}
\hline Drug & $N$ & $n_{\dagger}^{\dagger}$ & $n *$ & Sensitive & $\%$ & Resistant & $\%$ \\
\hline Rifampicin & 386 & 286 & 100 & 84 & 84.0 & 16 & 16.0 \\
\hline Isoniazid & 387 & 287 & 100 & 71 & 71.0 & 29 & 29.0 \\
\hline Ethambutol & 387 & 288 & 99 & 80 & 80.8 & 19 & 19.1 \\
\hline Streptomycin & 387 & 288 & 99 & 76 & 76.7 & 23 & 23.2 \\
\hline
\end{tabular}

Source: Authors' Original data

$N$, The total number of patients; $n$, Given as a means of number.

$\dagger$, Number of patients not tested.

$\downarrow$ Number of patients tested. 
TABLE 5: Distribution of retreatment tuberculosis patients by treatment outcome for patients followed up at the hospital $(N=214 *)$.

\begin{tabular}{lll}
\hline Treatment Outcome & $\boldsymbol{n}$ & $\mathbf{\%}$ \\
\hline Cured & 19 & 8.9 \\
Completed Treatment & 86 & 40.2 \\
Failure $\dagger$ & 9 & 4.2 \\
Defaulted & 49 & 2.9 \\
Death & 51 & 23.8 \\
\hline
\end{tabular}

Source: Authors' Original data

$N$, The total number of patients; $n$, Given as a means of number

${ }_{*}$, $(44.8 \%[174 / 388]$ patients were transferred to the clinics and records were not available for review)

$\uparrow$, Includes patients with MDR-TB $(n=7)$, MDR-TB rate of $3.3 \%$.

MDR, multidrug resistant.

the potential for the emergence of multidrug resistance TB which is an important and serious unsuccessful outcome of retreatment $\mathrm{TB}$.

The outcomes of retreatment TB in this study are only for those who were seen at the TB hospital and followed up on discharge. Those who defaulted on their treatment were those who were followed up as outpatients in the hospital after the initial phase of treatment. According to $\mathrm{WHO}^{2}$ the targets of TB programs for new PTB patients are smear-positive detection rates of $70 \%$ and a cure rate of $85 \%$. Whilst no specific targets for the outcomes have been set for retreatment $\mathrm{TB}$, it would be logical to assume that they should not be less than for new TB cases. In terms of the smear-positive detection rate, the TB programme at the hospital has been managed competently. It achieved $71 \%$ compared with the WHO-set target of 70\%, because the TB patients were mostly diagnosed with sputum smear microscopy. The treatment outcomes (cured and completed treatment) together were found to be $49.1 \%$. This is much less than the $73 \%$ reported by WHO in its 2005 global review of TB programmes. Of great significance is the 3.3\% MDR-TB found in this study. The MDR-TB is very expensive to treat and the longer treatment duration makes it difficult for patients to adhere to treatment. This proportion does not, however, derive from the estimated proportion of TB cases that were treated during the period which will lower the overall proportion. Amongst new TB cases in South Africa, previous studies had shown the MDR-TB rate to be relatively low at $1.6 \%$, whilst that for retreatment TB was $6.6 \%(4.0 \%-13.9 \%) \cdot{ }^{31}$ Compared to this, our figure of $3.3 \%$ for the retreatment $\mathrm{TB}$ cases is relatively small. This should, however, be seen against the setting that about $44 \%$ of the retreatment TB patients were transferred to other facilities for which information on outcomes was not available.

\section{Limitations of the study}

The study is limited by its design which is mainly descriptive and retrospective in nature. The study relies on the previously collected data and information on the patient file for analysis. Some of the information was incomplete, thus making it difficult to have a complete perspective of the problem under study. In situations where the diagnosis of TB was based on the chest radiograph, this information was accepted as it was recorded and the study did not seek to look at the chest radiograph in question. The treatment outcomes of patients discharged from the TB hospital and followed up at the clinics were not ascertained because of limited resources available to the researcher to visit the clinics and to collect the data needed.

The study is further limited by the fact that there is no control or comparison group on which to make an in-depth analytical appraisal of the identified related factors of retreatment TB. Time and resources had not made this possible. This aspect should be explored in a future study.

\section{Recommendations}

All TB patients (new or retreatment TB) should be offered voluntary counselling and testing for HIV, consistently. Those who are HIV-positive should be enrolled into ART programmes and monitored regularly to detect any deterioration in their immune status by regular CD4 measurements and necessary intervention should be started.

Improve process of care by appropriate and complete documentation in the patient file of all potential factors impacting on retreatment $\mathrm{TB}$ at the time of admission into the treatment programme and any new developments reviewed and updated as situations develop in the patients over the period of care. This will provide sufficient data on which the burden of the problem could be understood and allow dominant factors identified to be addressed with relevant interventions. Strengthening the institutional capacity to do this will be required in terms of personnel and other resources for monitoring and reporting on outcomes for retreatment TB patients.

Further researches should be undertaken that involve data collection from the patients, family and treatment partners directly, using quantitative and qualitative approaches to allow for quantitative analyses of factors and test associations with retreatment $\mathrm{TB}$.

\section{Conclusion}

This study has confirmed that some factors related to retreatment TB are similar to what were obtained elsewhere. In our situation majority of patients had completed $\mathrm{TB}$ treatment previously and default from treatment accounted for less than one quarter of the patients. There was a large proportion of non-documentation relating to drug resistance and sensitivity to TB drugs which reflects a serious lack of attention to this aspect of the care process for TB patients. The treatment outcomes (cured and completed treatment) together, were found to be much less than the reported target for TB programmes. For those tested for HIV, they were overwhelmingly positive. The quality of care for these patients needs to be improved by paying attention and documenting these factors. This study opens up areas of further research in our setting to test associations and prominence of some of the identified factors. 


\section{Acknowledgements}

I wish to express my unreserved and sincere thanks to Mrs C. Akpabio who supported and encouraged the study and read through the draft. I am also grateful to the manager of the TB hospital in Ermelo, Ms A. Pienaar, for her help in preparing the patient records for data collection as well as to the authorities of the Department of Health, Mpumalanga, for their permission to conduct the study. I thank Prof. M. Kidd of the Centre for Statistical Evaluation, University of Stellenbosch, who carried out the data analysis and initial data presentation. I would like to extend my appreciation to Prof. PJT. de Villiers who supervised the work from the outset. The study was funded from the resources of the study leader.

\section{Competing interests}

The authors declare that they have no financial or personal relationship(s) which may have influenced them inappropriately in writing this article.

\section{Authors' contributions}

U.S.A. was the main study leader responsible for identification of the study subject, the design of the data collection tool, the collection of data and its entry into the template for analysis, as well as the initial draft of the manuscript. P.J.T.V supervised the study from the onset, provided guidance and reviewed every stage of the study; he made substantial corrections and additions to the manuscript.

\section{References}

1. World Health Organisation. Treatment of tuberculosis: guidelines for Nationa Programmes. 3rd ed. Geneva: WHO Press; 2003.

2. World Health Organisation. Global tuberculosis control: surveillance, planning, financing. WHO Report 2007 WHO/HTM/TB/2007.376. [homepage on the internet] No date [cited 2008 Feb 10]. Available from: http://www.who.int/tb/ publications/global_report/2007/en/index.html

3. Department of Health and Social Services. Gert Sibande District 1st Quarter Review 2007/2008. District Health Office. Ermelo: Department of Health and Social Services, Mpumalanga.

4. Picon PD, Bassanesi SL, Camori MLA, Ferreira RLT, Jarczewski CA, De Borba Veira PR. Risk factors for recurrence of tuberculosis. J bras pneumol. 2007;33(5).

5. Lambert ML, Hasker E, Van Deun A, Roberfroid D, Boelaert M, Van der Stuft P. Recurrence in tuberculosis: relapse or re-infection? Lancet Infect Dis. 2002;3(5):282-282. $\mathrm{http} / / / \mathrm{dx}$.doi.org/10.1016/S1473-3099(03)00607-8

6. The South African Tuberculosis Control programme. Practical Guidelines. 2000. Pretoria: Department of Health.

7. Cox H, Morrow M, Deustschmann P. Long Term Efficacy of DOTS regimes for Tuberculosis: systematic review. BMJ. 2008;336(7642):484-487. http://dx.doi. org/10.1136/bmj.39463.640787.BE, PMid:18250104, PMCid:2258398

8. Sonnenberg P, Murray J, Glynn JR, Shearer S, Kambashi B, Godfrey-Faussett P. HIV 1 and recurrence, relapse, and re-infection of tuberculosis after cure: a cohort study in South African mineworkers. Lancet. 2002;359(9317):1618-1619; author reply $1619-1620$

9. Verver $\mathrm{S}$, Warren RM, Beyers $\mathrm{N}$, et al. Rate of re-infection tuberculosis after successful treatment is higher than rate of new tuberculosis. Am J Resp Crit Care Med. 2005;171(12):1430-1435. http://dx.doi.org/10.1164/rccm.20040912000C, PMid:15831840

10. Umubyeyi AN, Shamputa IC, Rigouts L, et al. Molecular investigation of recurrent tuberculosis in patients from Rwanda. Int J Tuberc Lung Dis. 2007;11(8):860-867. PMid:17705951

11. Shamputa IC, Van Deun A, Salim MA. Endogenous reactivation and true treatment failure as causes of recurrent tuberculosis in a high incidence setting with a low HIV infection. Trop Med Int Health. 2007;12(6):700-708. http://dx.doi. org/10.1111/j.1365-3156.2007.01840.x

12. VanRieA, WarrenR, Richardson M, etal.Exogenousre-infectionasacauseofrecurrent tuberculosis after curative treatment. N Engl J Med. 1999;341(16):1174-1179. http://dx.doi.org/10.1056/NEJM199910143411602, PMid:10519895
13. García de Viedma D, Marín M, Hernangómez S, et al. Tuberculosis recurrences: reinfection plays a role in a population whose clinical/epidemiological characteristics do not favor re-infection. Arch Intern Med. 2002;162(16):1873-1879. http:// do not favor re-infection. Arch Intern
dx.doi.org/10.1001/archinte.162.16.1873

14. Jasmer RM, Bozeman L, Schwartzman K, et al. Tuberculosis Trials Consortium (2004) Recurrent tuberculosis in the United States and Canada: relapse or re infection? Am J Respir Crit Care Med. 2004;170(12):1360-1366. http://dx.doi. infection? Am J Respir Crit Care Med. 2004;170(12):
org/10.1164/rccm.200408-10810C, PMid:15477492

15. Cacho J, Pérez Meixeira A, Cano I, et al. Recurrent tuberculosis from 1992 to 2004 in a metropolitan area. Eur Respir J. 2007;30(2):333-337. http://dx.doi. 2004 in a metropolitan area. Eur Respir J. 2007;
org/10.1183/09031936.00005107, PMid:17504801

16. El Sahly HM, Wright JA, Soini $\mathrm{H}$, et al. Recurrent tuberculosis in Houston, Texas: a population-based study. Int J Tuberc Lung Dis. 2004;8(3):333-340. PMid:15139472

17. Daniel OJ, Oladapo OT, Alausa OK. Default from tuberculosis treatment programme in Sagamu, Nigeria. Niger J Med. 2006;15(1):63-67. PMid:16649455

18. Salami AK, Oluboyo PO. Management outcome of pulmonary tuberculosis: a nine year review in llorin. West Afr J Med. 2003;22(2):114-119. PMid:14529217

19. Santha T, Garg R, Frieden TR, et al. Risk factors associated with default, failure and death among tuberculosis patients treated in a DOTS programme in Tiruvallu District, South India. Int J Tuberc Lung Dis. 2003;7(2):200-201. PMid:12588027

20. Dandona R, Dandona L, Mishra A, Dhingra S, Venkatagopalakrishna K, Chauhan LS Utilization of and barriers to public sector tuberculosis services in India. Natl Med J India. 2004;17(6):292-299. PMid:15736548

21. Lertmaharit $S$, Kamol-Ratankul $P$, Sawert $H$, Jittimanee $S$, Wangmanee $S$. Factors associated with compliance among tuberculosis patients in Thailand. J Med Assoc Thai. 2005;88(Suppl 4):S149-S156.

22. Ayama N, Sseguya S, Okwera A, El-Naggar WA, Mpagi F, Owino E. The challenge of re-treatment pulmonary tuberculosis at two teaching and referral hospitals in Uganda. African Health Sciences. 2007;7(3):136-142. PMid:18052866, PMCid:2269710

23. Kaona FA, Tuba M, Siziya S, Sikaona L. An assessment of factors contributing to treatment adherence and knowledge of TB transmission among patients on TB treatment. BMC Public Health. 2004;4:68. http://dx.doi.org/10.1186/1471-24584-68, PMid:15625004, PMCid:545081

24. Bam TS, Gunneberg C, Chamroonsawasdi K, et al. Factors affecting patient adherence to DOTS in urban Kathmandu, Nepal. Int J Tuberc Lung Dis. 2006;10(3):270-276. PMid:16562706

25. Talay F, Kumeti S, Altin S. Factors associated with treatment success for tuberculosis patients: a single center's experience in Turkey. Jpn J Infec Dis. 2008;6(1):25-30.

26. Mishra P, Hansen EH, Sabroe S, Kafle KK. Socio-economic status and adherence to tuberculosis treatment: a case-control study in a district of Nepal. Int J Tuberc Lung Dis. 2005;9(10):1134-1139. PMid:16229225

27. Jakubowiak WM, Bogorodskaya EM, Borisov SE, Danilova ID, Kourbatova EV Risk factors associated with default among new pulmonary TB patients and social support in six Russian regions. Int J Tuberc Lung Dis. 2007;11(1):46-53. PMid:17217129

28. Belo MT, Selig L, Luiz RR, et al. Choosing incentives to stimulate tuberculosis treatment compliance in a poor county in Rio de Janeiro state, Brazil. Med Sci Monit. 2006;12(5)

29. Thomas A, Gopi PG, Santha T, et al. Predictors of relapse among pulmonary tuberculosis patients treated in a DOTS programme in South India. Int J Tuberc Lung Dis. 2005;9(5):556-561. PMid:15875929

30. Davidson H, Schluger NW, Feldman PH, Valentine DP, Telzak EE, Laufer FN. The effects of increasing incentives on adherence to tuberculosis directly observed therapy. Int J Tuberc Lung Dis. 2000;4(9):860-865. PMid:10985655

31. National Tuberculosis Lead Programme, Medical Research Council. Factors associated with default from multidrug-resistant tuberculosis treatment, South Africa 1999-2001. Final results from a case-control study in 5 Provinces. Pretoria South Africa: ; 2005

32. Wares DF, Singh S, Acharya AK, Dangi R. Non-adherence to tuberculosis treatment in the eastern Tarai of Nepal. Int J Tuberc Lung Dis. 2003;7(4):327-335. PMid:12729337

33. Didilescu C, Ibraim E, Plopeanu D. A study of the risk factors for relapse in pulmonary tuberculosis patients and the results of the re-treatment. Pneumologia. 2000;49(4):247-252. PMid:11374385

34. Burukhina LV, Zolotovskaia EA, Prudnikova ZA, Vershinin AV, Kolmakova PL. Causes of recurrence of pulmonary tuberculosis: short and long term results of treatment. Probl Tuberk. 1995;3:29-31.

35. Mallory KF, Churchyard GJ, Kleinschmidt I, De Cock KM, Corbett EL. The impact of HIV infection on recurrence of tuberculosis in South African gold miners. Int Tuberc Lung Dis. 2000;4(5):455-462. PMid:10815740

36. Elliott AM, Halwiindi B, Hayes RJ, et al. The impact of human immunodeficiency virus on response to treatment and recurrence rate in patients treated for tuberculosis: two-year follow-up of a cohort in Lusaka, Zambia. J Trop Med Hyg. 1995;98(1):9-21. PMid:7861484

37. García Ordóñez MA, Martínez González J, Orihuela Cañadas F, Jiménez Oñate $F$, Colmenero Castillo JD. Recurrent tuberculosis in patients with co infection by HIV. Rev Clin Esp. 2003;203(6):279-283. PMid:12783713

38. Panjabi R, Comstock GW, Golub JE. Recurrent tuberculosis and its risk factors: adequately treated patients are still at high risk. Int J Tuberc Lung Dis. 2007;11(8):828-837. PMid:17705947 
39. Mishra P, Hansen EH, Sabroe S, Kafle KK. Adherence is associated with the quality of professional-patient interaction in Directly Observed Treatment Short-course,
DOTS. Patient Educ Couns. 2006;63(1-2):29-37. http://dx.doi.org/10.1016/j. DOTS. Patient Educ Couns. $2006 ; 6$
pec.2005.08.006, PMid:16242297

40. Jaiswal A, Singh V, Ogden JA, et al. Adherence to tuberculosis treatment: lessons from the urban setting of Delhi, India. Trop Med Int Health. 2003;8(7):625-633. http://dx.doi.org/10.1046/j.1365-3156.2003.01061.x, PMid:12828545

41. Johnson JL, Okwera A, Vjecha MJ, et al. Risk factors for relapse in human immunodeficiency virus type 1 infected adults with pulmonary tuberculosis. Int J Tuberc Lung Dis. 1997;1(5):446-453. PMid:9441100

42. Alrajhi AA, Abdulwahab S, Almodovar E, Al-Abdely HM. Risk factors for drug-resistant Mycobacterium tuberculosis in Saudi Arabia. Saudi Med $J$ drug-resistant Mycobacterium tube
2002;23(3):305-310. PMid:11938422

43. Wilkinson D, Pillay M, Davies GR, Sturm AW. Resistance to antituberculosis drugs in rural South Africa: rates, patterns, risks, and transmission dynamics. Trans R Soc Trop Med Hyg. 1996;90(6):692-695. http://dx.doi.org/10.1016/S00359203(96)90440-X

44. Churchyard GJ, Corbett EL, Kleinschmidt I, Mulder D, De Cock KM. Drug-resistant tuberculosis in South African gold miners: incidence and associated factors. Int Tuberc Lung Dis. 2000;4(5):433-440. PMid:10815737
45. Murray J, Sonnenberg P, Shearer SC, Godfrey-Faussett P. Human immunodeficiency virus and the outcome of treatment for new and recurrent pulmonary virus and the outcome of treatment for new and recurrent pulmonary
tuberculosis in African patients. Am J Respir Crit Care Med. 1999;159(3):733-740. PMid:10051244

46. Murray J, Sonnenberg P, Shearer S, Godfrey-Faussett P. Drug-resistant pulmonary tuberculosis in a cohort of southern African gold miners with a high prevalence of tuberculosis in a cohort of southern African gold miners with a high
HIV infection. S Afr Med J. 2000;90(4):381-386. PMid:10957924

47. Salaniponi FM, Nyirenda TE, Kemp JR, Squire SB, Godfrey-Faussett $P$, Harries AD. Characteristics, management and outcome of patients with recurrent tuberculosis under routine programme conditions in Malawi. Int J Tuberc Lung tuberculosis under routine programme
Dis. 2003;7(10):948-952. PMid:14552564

48. Pulido F, Pena JM, Rubio R, Moreno, S, Gonzalez J, Guijaro C. Relapse of tuberculosis after treatment in human immunodeficiency virus infected patients. Arch Intern
Med. 1997;157(2):227-232. http://dx.doi.org/10.1001/archinte.157.2.227, Med. 1997; 1 Mid:900982

49. Nettles RE, Mazo D, Alwood K, Gachuhi R, Maltas G, Wendel K. Risk factors for relapse and acquired rifamycin resistance after directly observed tuberculosis treatment: a comparison of HIV serostatus and rifamycin use. Clin Infect Dis. 2004;38(5)731-736. http://dx.doi.org/10.1086/381675, PMid:14986259 